\title{
From Field to Filed: Minimising and Mitigating Risks of Data Error and Loss in a Vertebrate Zoology Collection
}

\author{
Karen K. Roberts $\ddagger$ \\ ‡ Museums Victoria, Melbourne, Australia
}

Corresponding author: Karen K. Roberts (karoberts@museum.vic.gov.au)

Received: 02 May 2018 | Published: 13 Jun 2018

Citation: Roberts K (2018) From Field to Filed: Minimising and Mitigating Risks of Data Error and Loss in a Vertebrate Zoology Collection. Biodiversity Information Science and Standards 2: e26344.

https://doi.org/10.3897/biss.2.26344

\begin{abstract}
One of the key risks identified for the Vertebrate Zoology (VZ) Collections at Museums Victoria has been data error, loss and dissociation. These risks are highest during the stages involved in preparing the specimen for lodgement in the collection (from collecting and accession of the specimen, to preparation, labelling and so on). The VZ Collections data are managed through an electronic collection information system (EMu) but the process of data transferral and input can be time-consuming and error-prone at many steps along the way. The two main methods of specimen acquisition in the Mammalogy, Ornithology and Herpetology collections in recent years have been internal field programs and external stakeholder donations. Prior to 2012, most specimen data from both of these methods of acquisition were handwritten and transcribed one or more times by multiple people before a specimen ended up in the primary database. An assortment of other identifying numbers or codes were used prior to a collection number being assigned, and sometimes these have been difficult to match up or reconcile. The amount of time needed to enter this information manually also increased the risk of data dissociation and specimen misplacement, as it could significantly delay getting specimens lodged correctly in the collection.
\end{abstract}


Since 2012, a number of steps have been taken by the VZ Collection staff to reduce these risks and streamline data processing. For internal field programs in Mammalogy and Ornithology, a field data-collecting tool has been developed using FileMaker Pro. This enables direct input of specimen and field data into our FileMaker field database using the FileMaker Go app on iPad that is then exportable to an Excel spreadsheet for upload to $\mathrm{EMu}$. Specimens are given field numbers initially, and a collection number once at the museum. Data processing is simplified as most specimens undergo full preparation in the field. We have also developed an upload spreadsheet in Excel that can be used by internal or external researchers who are lodging bulk lots of specimens. Thus we receive the mandatory data we require, and it is already in a format we can easily upload to EMu. For external stakeholder donations, preparation is completed at the museum so all data available upon donation are entered directly into EMu. A collection registration number is applied as soon as a specimen is accessioned so there is only one number required to track it during and after preparation. All specimen-related data generated during preparation are still handwritten and then transcribed direct to the electronic catalogue record by collection managers.

These procedures continue to be refined, but have significantly enhanced specimen and associated data management. Accidental data loss through technical issues, for example possible iPad data-loss before backup, human error at data input stage such as overwriting a record, or incorrectly assigning field number, have been minimal. Also, we will continue to decrease the need for data transcription by encouraging internal and external researchers to use our data-upload spreadsheet, and training preparation staff to enter specimen data directly into the specimen catalogue record in EMu.

\section{Keywords}

Data, Vertebrate, Zoology, Mammalogy, Ornithology, Database, Poster

\section{Presenting author}

Karen K. Roberts 